University of Nebraska - Lincoln

DigitalCommons@University of Nebraska - Lincoln

Faculty Papers and Publications in Animal

Science

Animal Science Department

1995

\title{
The Effects of Orientation and Storage Time on the Prediction of Beef Rib Composition Using Electromagnetic Scanning
}

\author{
B. L. Gwartney \\ University of Nebraska-Lincoln \\ N. L. Meseck \\ University of Nebraska-Lincoln \\ Chris R. Calkins \\ University of Nebraska-Lincoln, ccalkins1@unl.edu
}

Follow this and additional works at: https://digitalcommons.unl.edu/animalscifacpub

Part of the Animal Sciences Commons

Gwartney, B. L.; Meseck, N. L.; and Calkins, Chris R., "The Effects of Orientation and Storage Time on the Prediction of Beef Rib Composition Using Electromagnetic Scanning" (1995). Faculty Papers and Publications in Animal Science. 592.

https://digitalcommons.unl.edu/animalscifacpub/592

This Article is brought to you for free and open access by the Animal Science Department at DigitalCommons@University of Nebraska - Lincoln. It has been accepted for inclusion in Faculty Papers and Publications in Animal Science by an authorized administrator of DigitalCommons@University of Nebraska - Lincoln. 


\title{
The Effects of Orientation and Storage Time on the Prediction of Beef Rib Composition Using Electromagnetic Scanning ${ }^{1,2}$
}

\author{
B. L. Gwartney, N. L. Meseck, and C. R. Calkins \\ Animal Science Department, University of Nebraska, Lincoln 68583-0908
}

\begin{abstract}
To investigate the effects of orientation of beef ribs in an electromagnetic field and storage time on the prediction of rib composition, 64 ribs (IMPS 103) were scanned $(2.5 \mathrm{MHz})$ in three different orientations: posterior end first (POS), dorsal end first (DOR), and fat side first, blade end down (BLD). Scans were obtained after 1 and $5 \mathrm{~d}$ of storage. Scan peak, rib weight, $3 / 4$ fat depth, length, and temperature were used to predict percentage and weight of dissectable and fat-free lean. The mean peak for the BLD scans was four to six times higher than the POS or DOR scans. Ribs scanned in the BLD orientation on $d 5$ had the highest coefficient of determination (CD; 94.0) and the lowest residual standard deviation (RSD; $.22 \mathrm{~kg}$ ) for prediction of lean weight. The POS and DOR scans were similar at
\end{abstract}

$\mathrm{d} 5(\mathrm{CD}=91.4$ and 90.3 , respectively) with RSD of .30 and $.31 \mathrm{~kg}$, respectively. Prediction of lean percentage resulted in lower $C D$ than predicting lean weight. For percentage of lean, BLD scans at $d 5$ once again resulted in the best $C D$ (81.6) and lowest RSD $(1.5 \%)$. Prediction of percentage lean using POS or DOR orientation resulted in CD of 71.2 and 67.1 and RSD of 2.0 and $2.1 \%$, respectively. The CD were similar for POS and DOR scans at $\mathrm{d} 1$ and $\mathrm{d} 5$. Predicting fat-free lean weight resulted in equal or lower CD than dissected lean and higher CD for lean percentage. It seems that orientation during scanning, when consistent, is not a major concern. As the time between scanning and dissection increases, dehydration weight loss may need to be measured.

Key Words: Electromagnetic Field, Beef, Composition

J. Anim. Sci. 1995. 73:387-392

\section{Introduction}

Several studies have indicated that electromagnetic scanning (EMS) is capable of accurately determining the lean content of beef (Gwartney et al., 1992) and pork (Forrest et al., 1989) primals, quarters, and carcasses. Gwartney et al. (1992) presented a coefficient of determination (CD) of 91.0 and residual standard deviation (RSD) of $1.1 \mathrm{~kg}$ for predicting hindquarter lean content by scanning hindquarters. For the primal rib these numbers were much lower $(C D=68.8$ and $\mathrm{RSD}=.4)$. The resulting low $\mathrm{CD}$ for the rib are partly due to the size of the cut that is being scanned in relation to the scanning unit and magnetic coil diameter. Lin et al. (1992) indicated that the size of the cut is very important in predicting lean content, stating that for small cuts such as the rib or brisket cut weight is more important than peak

\footnotetext{
${ }^{1}$ Published as paper no. 10687, journal series, Nebraska Agric. Res. Div.

${ }^{2}$ Supported in part by a grant from the Beef Industry Council of the National Live Stock and Meat Board.

Received May 9, 1994.

Accepted September 20, 1994.
}

response or conductivity. For larger cuts such as the loin, round, and chuck, the conductivity index (peak scan) is more important than weight. These studies, however, do not address the importance of orientation of the cut, geometry effects, or water loss on the prediction of lean content.

The geometry and orientation of a cut being scanned are important factors that determine response within the EMS unit. To account for some of the sample variability in geometry of pigs, Fiorotto et al. (1987) used the equation of weight/length ${ }^{2}$, and this increased $r$ values when measuring fat-free mass and total body water.

Although the EMS unit does not scan individual cross-sections, the relationship between cross-sectional area and scan peak makes this a useful analogy to explain the influence of orientation on scan peak. A rib that is scanned in a posterior position has a small transverse cross-sectional area, and a rib scanned fat side first with the blade end down would have a much greater cross-sectional area and a higher peak reading. It was hypothesized that the orientation presenting the largest cross-sectional area would yield more precise predictions, partly because of a lower signal: noise ratio. In addition, size and shape need to be 
Table 1. Means for rib characteristics and the scan peaks at various orientations and storage times

\begin{tabular}{|c|c|c|c|c|c|c|}
\hline Trait & Mean & $\mathbf{n}$ & $\mathrm{SD}$ & Minimum & Maximum & $\mathrm{CV}^{\mathrm{a}}$ \\
\hline \multicolumn{7}{|l|}{ Rib characteristic } \\
\hline Weight, kg & 14.62 & 64 & 1.93 & 10.06 & 18.37 & 13.21 \\
\hline $3 / 4$ Fat thickness, cm & .97 & 64 & .35 & .30 & 1.98 & 36.39 \\
\hline Temperature, d 1 & .90 & 64 & .85 & -.33 & 2.99 & 92.12 \\
\hline Temperature, d 5 & 3.60 & 59 & 2.66 & -.39 & 8.38 & 73.62 \\
\hline Posterior ${ }^{b}$ length, $\mathbf{c m}$ & 46.30 & 64 & 2.58 & 40.64 & 50.80 & 5.58 \\
\hline Dorsal $^{\mathrm{c}}$ length, $\mathrm{cm}$ & 30.60 & 64 & 11.88 & 16.51 & 44.45 & 38.72 \\
\hline Blade $^{\mathrm{d}}$ length, $\mathrm{cm}$ & 25.20 & 48 & 2.33 & 20.32 & 31.75 & 9.22 \\
\hline \multicolumn{7}{|l|}{ Scanned peak ${ }^{e}$} \\
\hline Posterior peak, d 1 & 17.47 & 64 & 3.36 & 9.10 & 26.60 & 19.23 \\
\hline Posterior peak, d 5 & 17.68 & 60 & 3.17 & 10.00 & 26.21 & 17.92 \\
\hline Dorsal peak, d 1 & 27.24 & 64 & 4.71 & 14.65 & 38.45 & 17.30 \\
\hline Dorsal peak, d 5 & 27.00 & 60 & 4.40 & 15.30 & 37.00 & 16.30 \\
\hline Blade peak, d 1 & 110.51 & 45 & 16.52 & 75.90 & 138.60 & 14.94 \\
\hline Blade peak, d 5 & 111.73 & 42 & 16.50 & 75.65 & 144.70 & 14.77 \\
\hline
\end{tabular}

${ }^{\mathrm{a}} \mathrm{CV}=$ coefficient of variation.

bosterior represents ribs scanned posterior end first, fat side down.

'Dorsal represents ribs scanned dorsal side first, fat side down.

${ }^{\mathrm{d}}$ Blade represents ribs scanned blade end down, fat side first.

e Scan peak is a unitless index of energy absorbed from the electromagnetic field.

considered in the selection of a prediction model because the EMS signal is influenced not only by the subject's conductive mass but also by its geometry (Klish et al., 1984).

Water content and the effect of water loss or dehydration on the EMS peak response may also be important. The EMS reading is a function of the conductive and dielectric properties of the fat-free mass (Pethig, 1979; Khaled et al., 1985). Based on this concept, the signal from a fresh rib that has normal water and electrolyte contents may elicit a higher response than that from a rib that has been dehydrated due to normal aging. If this difference is measurable, the time delay between scanning and dissection could ultimately affect the accuracy of prediction. The objectives of this study were to investigate the effects orientation in a magnetic field and storage time have on the prediction of beef rib composition.

\section{Materials and Methods}

Sixty-four ribs (IMPS 103) varying in composition were obtained from beef heifers (USDA, 1988). Carcass yield and quality data, according to USDA standards, were obtained $3 \mathrm{~d}$ postmortem on the carcasses before the ribs were shipped to the University of Nebraska-Lincoln Meat laboratory. Before scanning in an MQ-27 model electromagnetic scanning unit (Meat Quality Incorporated, Springfield, IL), rib weight (fresh and after $5 \mathrm{~d}$ of storage) was recorded using a digital scale. Internal temperature was recorded using an Omega 450 ATT thermocouple thermometer type T (Stamford, CT) inserted $18 \mathrm{~cm}$ into the longissimus muscle at the anterior end of the rib.
Ribs were scanned in duplicate using three different orientations: posterior end first, fat side down ( POS); dorsal end first, fat side down ( DOR); and blade end down, fat side first ( BLD). Scans were obtained after two different storage times (the day of receiving the ribs from the packing plant ( $\mathrm{d} 1 ; 5 \mathrm{~d}$ postmortem) and after an additional $5 \mathrm{~d}$ of unbagged storage in the cooler ( $d$ 5).

All ribs were dissected within $2 \mathrm{~d}$ of the 5-d scan. Each rib was separated into a 9-10-11 rib section and a remaining portion as described by Hankins and Howe (1946). These components were then separated into lean (trimmed free of all visible fat), fat (subcutaneous and intermuscular), and bone. All lean from the 9-10-11 rib section and the remaining sections were separately ground through a kidney plate $(25 \mathrm{~mm} \times 50 \mathrm{~mm})$ and mixed. Half the kidney-plate-ground lean was ground through a $20-\mathrm{mm}$ plate and mixed, and half that lean was ground through a 5-mm plate. A .5-kg subsample was double-bagged and frozen for proximate analysis (within $3 \mathrm{mo}$ ). For analysis, frozen samples were chopped into small pieces and powdered in a Waring blender (New Hartford, CT) containing liquid nitrogen. A representative sample was analyzed for moisture, lipid, and protein content (AOAC, 1990). This protocol was followed to calculate a fat-free, dissected lean component for use as a dependent variable in the linear regression analysis.

Linear regression analyses were performed using total dissected lean weight (kilograms) and percentage of lean (fat-free and dissected lean for both) with an adjustment for dehydration weight loss as the dependent variables (SAS, 1990). These dependent variables were calculated several ways; explanations and means are presented in Table 1 . Rib weight ( $d 1$ 


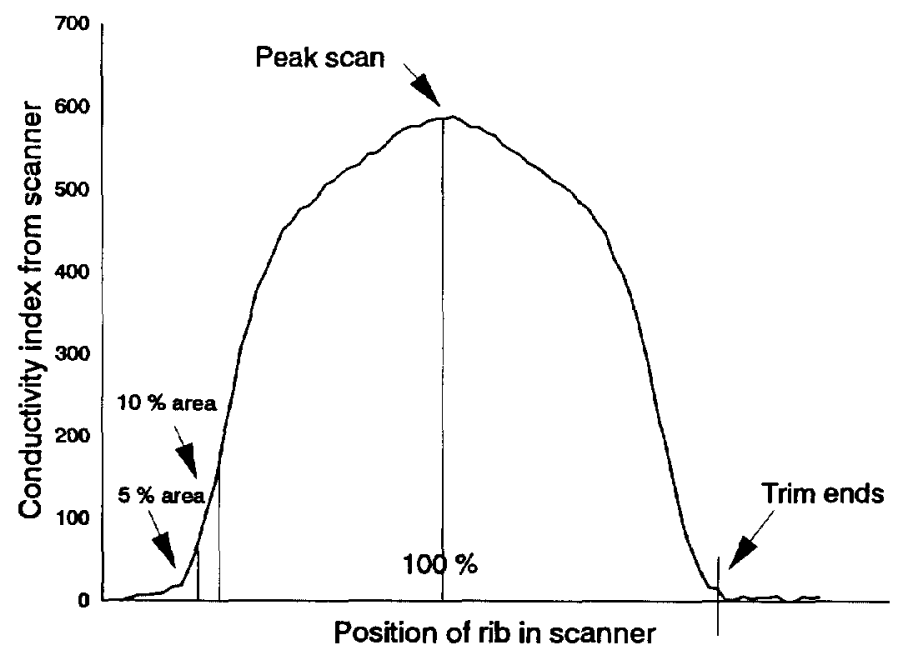

Figure 1. Illustration of scanning curve and peak extractions with software.

and 5), length (longest linear length when oriented for scanning), temperature (d 1 and 5), scanning peak ( $\mathrm{d} 1$ and 5 ), and $3 / 4$ fat depth were the independent variables. The best prediction model was selected by maximizing the CD, minimizing the RSD, and selecting the $\mathrm{Cp}$ statistic that approaches number of parameters in the model, including the intercept. Mallows' $\mathrm{Cp}$ statistic is a quantitative measure of any bias that may exist in a prediction model. The CD represents the amount of variation explained by the best model obtained from scanning, and the RSD indicates the standard deviation of the predicted value.

The scanning curves were smoothed (Figure 1) using custom-written software that trims either side of the curve of any negative values and then performs a continuous rolling average of 10 consecutive scan numbers. The initial peak (without smoothing), a smoothed peak, and the initial peak averaged with the five numbers on either side of the peak (smoothed average) were recorded. Smoothing of the curve is useful because the signal to noise ratio may be minimized. The scanning unit was calibrated to record 40 readings per second, with a belt speed $40 \%$ of maximum (about $.5 \mathrm{~m} / \mathrm{s}$ ). Rib scans took approximately $4.5 \mathrm{~s}$.

\section{Results and Discussion}

Initial analyses of the three different methods to determine peak were performed to find the best peak measurement to predict lean. The smoothed average peak was most often the measure most highly related to composition (data not included) and is used throughout the paper. All the results tables contain the coefficients of determination (CD), residual standard deviations (RSD), Mallows' Cp statistic (Mallows, 1973), and regression coefficients for the best model.

Although the study initially contained 64 ribs, several were dissected before the 5-d storage period was complete. Some observations were also lost when ribs were inadvertently dissected before completion of the scanning sequence. Thus, the number of observations for different orientations and storage times was variable (Table 1). The BLD scans were four to six times higher than the POS and DOR scans. The peak scans would be expected to be higher at $d 1$ than at $d 5$ because the ribs have not lost as much weight due to

Table 2. Calculated rib lean content means used as the dependent variable lean end points

\begin{tabular}{|c|c|c|c|c|c|c|c|}
\hline Trait & $\begin{array}{l}\text { Scan } \\
\text { date }\end{array}$ & Mean & $\mathrm{n}$ & SD & Minimum & Maximum & $C V^{a}$ \\
\hline Rib lean, $\mathrm{kg}^{\mathrm{b}}$ & Day 1 & 7.36 & 63 & .97 & 4.88 & 9.30 & 13.24 \\
\hline Rib lean, $\%_{0}^{\mathrm{c}}$ & Day 1 & 50.25 & 63 & 3.41 & 41.72 & 60.00 & 6.80 \\
\hline Rib lean, $\mathrm{kg}^{\mathrm{d}}$ & Day 5 & 7.08 & 59 & .96 & 4.59 & 9.03 & 13.64 \\
\hline Rib lean, $\%^{\mathrm{e}}$ & Day 5 & 49.14 & 59 & 3.52 & 40.78 & 59.04 & 7.17 \\
\hline Fat-free, $\mathrm{kg}^{f}$ & Day 1 & 6.81 & 62 & .89 & 4.63 & 8.55 & 12.99 \\
\hline Fat-free, & Day 1 & 46.72 & 62 & 3.85 & 37.66 & 59.13 & 8.25 \\
\hline Fat-free, $\mathrm{kg}^{\mathrm{h}}$ & Day 5 & 6.54 & 58 & .88 & 4.34 & 8.30 & 13.47 \\
\hline Fat-free, $\%$ i & Day 5 & 45.59 & 58 & 3.96 & 36.62 & 58.15 & 8.69 \\
\hline
\end{tabular}

${ }^{a} \mathrm{CV}=$ coefficient of variation.

${ }^{b}$ Dissected lean weight plus the weight loss between $d-1$ weight and dissection weight.

cDissected lean percentage using $d-1$ weight in percentage calculation and the addition of the weight loss between $d-1$ weight and dissection weight.

dDissected lean weight plus the weight loss between d-5 weight and dissection weight.

e Dissected lean percentage using $d-5$ weight in percentage calculation and the addition of the weight loss between $d-5$ weight and dissection weight.

${ }^{f}$ Dissected lean weight (fat-free) plus the weight loss between d-1 weight and dissection weight.

gissected lean percentage (fat-free) plus the weight loss between d-1 weight and dissection weight.

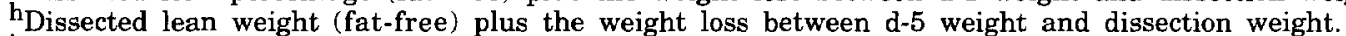

${ }^{i}$ Dissected lean percentage (fat-free) plus the weight loss between $\mathrm{d}-5$ weight and dissection weight. 
Table 3. Regression equations predicting dissected lean weight and percentage for fresh ribs with an adjustment for weight loss (d 1 to dissection) ${ }^{a}$

\begin{tabular}{|c|c|c|c|c|c|c|c|c|c|}
\hline \multirow[b]{2}{*}{ Variable } & \multirow[b]{2}{*}{$\mathrm{CD}^{\mathrm{b}}$} & \multirow[b]{2}{*}{$\mathrm{Cp} \mathrm{p}^{\mathrm{c}}$} & \multirow[b]{2}{*}{$\mathrm{RSD}^{\mathrm{d}}$} & \multicolumn{6}{|c|}{ Regression coefficient } \\
\hline & & & & Intercept & Peak & Length & Temp. & $3 / 4$ Fat & Weight \\
\hline \multicolumn{10}{|l|}{ Weight of lean, $\mathrm{kg}$} \\
\hline Posterior, d-1 scan & 91.32 & 5.331 & .2997 & -.069 & .1577 & .0519 & -.1747 & -.6216 & .2111 \\
\hline Posterior, d-5 scan & 91.35 & 5.001 & .2974 & -.006 & .1734 & .0646 & -.0860 & -.5269 & .1527 \\
\hline Dorsal, d-1 scan & 90.11 & 3.148 & .3171 & 1.1834 & .0996 & - & -.1630 & -.6721 & .2955 \\
\hline Dorsal, d-5 scan & 90.32 & 3.414 & .3119 & 1.4300 & .1175 & - & -.0543 & -.6193 & .2536 \\
\hline Blade, d-1 scan & 91.25 & 4.628 & .2755 & -.269 & .0250 & - & -.1137 & -.4503 & .3692 \\
\hline Blade, d-5 scan & 94.01 & 4.185 & .2243 & .9025 & .0339 & - & -.0926 & - & .2058 \\
\hline \multicolumn{10}{|l|}{ Percentage of lean } \\
\hline Posterior, d-1 scan & 69.42 & 5.212 & 1.971 & 50.174 & 1.0976 & .3426 & -1.1970 & -3.9758 & -2.0180 \\
\hline Posterior, d-5 scan & 71.22 & 5.042 & 1.978 & 50.600 & 1.1727 & .4302 & -.6609 & -3.2705 & -2.4363 \\
\hline Dorsal, d-1 scan & 63.72 & 3.227 & 2.128 & 58.192 & .6808 & - & -1.0994 & -4.3725 & -1.4157 \\
\hline Dorsal, d-5 scan & 67.11 & 3.173 & 2.095 & 60.011 & .7868 & - & -.4424 & -3.9288 & -1.7376 \\
\hline Blade, $\mathrm{d}-1$ scan & 70.67 & 5.007 & 1.920 & 43.407 & .1677 & .2358 & -1.0269 & -3.3406 & -.9108 \\
\hline Blade, d-5 scan & 81.56 & 3.994 & 1.549 & 55.286 & .2118 & - & -.6250 & -2.1849 & -1.6981 \\
\hline
\end{tabular}

aThe weight loss between time of $d-1$ scanning and time of dissection.

${ }^{\mathrm{b}_{\mathrm{CD}}}=$ coefficient of determination.

${ }^{c} \mathrm{Cp}=$ Mallows' $\mathrm{Cp}$ statistic for model selection.

${ }^{\mathrm{d}}$ RSD = residual standard deviation (kilograms), percentage on bottom half.

dehydration. Except for DOR scans, however, this was not correct. This can probably be attributed to the difference in mean temperature at $\mathrm{d} 1$ and 5 ; d-5 temperature was higher, which creates greater conductivity. This occurred because our storage cooler was not as cold as the meat on arrival. Therefore, temperature becomes an important variable in the prediction model if variation in temperature exists. Table 2 contains the lean weight and percentage end points, including fat-free calculations, used for regression.
Ribs scanned in the BLD orientation on $\mathrm{d} 5$ had the highest CD (94.0) and the lowest RSD (.22 kg) for predicting adjusted lean weight (kilograms) than any other scanning combinations (Table 3 ), although the differences were small in magnitude. These values are higher than those reported by Gwartney et al. (1992), but in that study no fat depth measurement or weight of the rib was used in the prediction model. Also, only the POS orientation was used and no smoothing of the scan curve was used, which would have produced a better scan curve and peak for the rib analysis.

Table 4. Regression equations predicting dissected lean weight and percentage for aged ribs with an adjustment for weight loss (d 5 to dissection) $)^{\mathrm{a}}$

\begin{tabular}{|c|c|c|c|c|c|c|c|c|c|}
\hline \multirow[b]{2}{*}{ Variable } & \multirow[b]{2}{*}{$\mathrm{CD}^{\mathrm{b}}$} & \multirow[b]{2}{*}{$\mathrm{Cp}^{\mathrm{c}}$} & \multirow[b]{2}{*}{$\mathrm{RSD}^{\mathrm{d}}$} & \multicolumn{6}{|c|}{ Regression coefficient } \\
\hline & & & & Intercept & Peak & Length & Temp. & 3/4 Fat & Weight \\
\hline \multicolumn{10}{|l|}{ Weight of lean, $\mathrm{kg}$} \\
\hline Posterior, d-1 scan & 91.24 & 5.908 & .2994 & -.119 & .1584 & .0474 & -.1876 & -.6035 & .2073 \\
\hline Posterior, d-5 scan & 91.42 & 5.023 & .2963 & -.045 & .1677 & .0628 & -.0992 & -.5088 & .1501 \\
\hline Dorsal, d-1 scan & 89.50 & 3.183 & .3247 & 1.1508 & .0908 & -.0032 & -.1530 & -.6623 & .2858 \\
\hline Dorsal, d-5 scan & 90.24 & 3.473 & .3131 & 1.3304 & .1120 & - & -.0674 & -.6062 & .2530 \\
\hline Blade, d-1 scan & 90.55 & 4.013 & .2900 & -.618 & .0229 & - & -.1196 & -.5340 & .3965 \\
\hline Blade, d-5 scan & 94.03 & 3.476 & .2246 & .7754 & .0328 & - & -.1039 & - & .2064 \\
\hline \multicolumn{10}{|l|}{ Percentage of lean } \\
\hline Posterior, d-1 scan & 71.01 & 5.464 & 1.987 & 49.220 & 1.1505 & .3339 & -1.2701 & -3.9543 & -2.0571 \\
\hline Posterior, d-5 scan & 70.32 & 5.023 & 2.011 & 49.392 & 1.1756 & .4344 & -.7231 & -3.2900 & -2.4228 \\
\hline Dorsal, d-1 scan & 63.42 & 3.055 & 2.212 & 56.262 & .6839 & - & -1.1478 & -4.4539 & -1.3546 \\
\hline Dorsal, d-5 scan & 65.96 & 3.172 & 2.134 & 58.870 & .7854 & - & -.5011 & -3.9686 & -1.7084 \\
\hline Blade, d-1 scan & 68.45 & 4.405 & 2.055 & 46.138 & .1690 & - & -.8077 & -3.8750 & -.7486 \\
\hline Blade, d-5 scan & 79.92 & 3.903 & 1.602 & 56.100 & .2367 & - & -.7944 & - & -2.1393 \\
\hline
\end{tabular}

${ }^{2}$ The weight loss between time of $d-5$ scanning and time of dissection.

${ }^{\mathrm{b}} \mathrm{CD}=$ coefficient of determination.

${ }^{c} \mathrm{Cp}=$ Mallows' $\mathrm{Cp}$ statistic for model selection.

${ }^{d} \mathrm{RSD}=$ residual standard deviation (kilograms), percentage on bottom half. 
Table 5. Regression equations predicting fat-free lean weight and percentage for fresh ribs with an adjustment for weight loss (d 1 to dissection) ${ }^{\mathrm{a}}$

\begin{tabular}{|c|c|c|c|c|c|c|c|c|c|}
\hline \multirow[b]{2}{*}{ Variable } & \multirow[b]{2}{*}{$\mathrm{CD}^{\mathrm{b}}$} & \multirow[b]{2}{*}{$\mathrm{Cp}^{\mathrm{c}}$} & \multirow[b]{2}{*}{$\operatorname{RSD}^{\mathrm{d}}$} & \multicolumn{6}{|c|}{ Regression coefficient } \\
\hline & & & & Intercept & Peak & Length & Temp. & 3/4 Fat & Weight \\
\hline \multicolumn{10}{|l|}{ Weight of lean, $\mathrm{kg}$} \\
\hline Posterior, d-1 scan & 89.71 & 5.929 & .2965 & .2684 & .1798 & .0567 & -.1627 & -.7028 & .1155 \\
\hline Posterior, d-5 scan & 89.39 & 3.532 & .2988 & .1547 & .2076 & .0848 & -.0997 & -.5140 & - \\
\hline Dorsal, d-1 sean & 88.15 & 3.007 & .3154 & 1.6329 & .1153 & - & -.1536 & -.7528 & .2049 \\
\hline Dorsal, d-5 scan & 88.47 & 3.506 & .3115 & 1.8262 & .1338 & - & -.0515 & -.6952 & .1638 \\
\hline Blade, d-1 scan & 89.31 & 5.700 & .2888 & -.943 & .0271 & .0429 & -.1497 & -.4994 & .2949 \\
\hline Blade, d-5 scan & 92.27 & 4.582 & .2422 & .8315 & .0332 & - & -.0718 & -.3963 & .2026 \\
\hline \multicolumn{10}{|l|}{ Percentage of lean } \\
\hline Posterior, $\mathrm{d}-1$ scan & 75.86 & 5.416 & 1.977 & 49.509 & 1.2472 & .3580 & -1.1011 & -4.4631 & -2.4132 \\
\hline Posterior, d-5 scan & 76.33 & 5.027 & 2.025 & 48.700 & 1.3170 & .4759 & -.6458 & -3.6883 & -2.8488 \\
\hline Dorsal, d-1 scan & 70.74 & 3.096 & 2.157 & 57.736 & .7836 & - & -1.0222 & -4.8600 & -1.7875 \\
\hline Dorsal, d-5 scan & 73.61 & 3.113 & 2.117 & 59.225 & .9029 & - & -.4139 & -4.3474 & -2.1221 \\
\hline Blade, d-1 scan & 73.40 & 5.677 & 2.059 & 40.112 & .1875 & .3263 & -1.0700 & -3.6699 & -1.2168 \\
\hline Blade, d-5 scan & 82.23 & 6.975 & 1.742 & 49.893 & .2254 & .1763 & -.6426 & -2.5764 & -1.9575 \\
\hline
\end{tabular}

aThe weight loss between time of $d-1$ scanning and time of dissection.

${ }^{\mathrm{b}} \mathrm{CD}=$ coefficient of determination.

${ }^{c_{C p}} \mathrm{C}$ Mallows' Cp statistic for model selection.

${ }_{\mathrm{d}}^{\mathrm{RSD}}=$ residual standard deviation (kilograms), percentage on bottom half.

For percentage of lean (Table 3), BLD scans at d 5 once again resulted in the best $\mathrm{CD}(81.6)$ and lowest RSD (1.5\%). For all orientations the CD were lower when predicting percentage lean vs weight (kilograms). This is expected because the scanning unit cannot distinguish fat and only measures lean. Fat, however, is important in the calculation of lean percentage. For this reason, $3 / 4$ fat depth is an important variable to include in the percentage lean prediction model, as is the weight of the cut.

Loss of rib weight was minimal over the 5-d storage period but when added back to the dissected lean weight was important in the dependent variable end point calculation (Table 4). The DOR scan CD increased only approximately $1 \%$ for predicting weight and $4 \%$ for percentage of lean between $\mathrm{d} 1$ and 5 , whereas the BLD scan CD increased 3 and $11 \%$, respectively, between $d 1$ and 5 . The POS scans were similar between $\mathrm{d} 1$ and $\mathrm{d} 5$.

When a fat-free lean component was calculated, the percentage lean prediction was increased up to $5 \%$, depending on which orientation was used (Table 5

Table 6. Regression equations predicting fat-free lean weight and percentage for aged ribs with an adjustment for weight loss (d 5 to dissection) $)^{\mathrm{a}}$

\begin{tabular}{|c|c|c|c|c|c|c|c|c|c|}
\hline \multirow[b]{2}{*}{ Variable } & \multirow[b]{2}{*}{$\mathrm{CD}^{\mathrm{b}}$} & \multirow[b]{2}{*}{$\mathrm{Cp}^{\mathrm{c}}$} & \multirow[b]{2}{*}{$\operatorname{RSD}^{\mathbf{d}}$} & \multicolumn{6}{|c|}{ Regression coefficient } \\
\hline & & & & Intercept & Peak & Length & Temp. & $3 / 4$ Fat & Weight \\
\hline \multicolumn{10}{|l|}{ Weight of lean, kg } \\
\hline Posterior, d-1 scan & 89.41 & 6.727 & .3003 & .1443 & .1769 & .0547 & -.1784 & -.6801 & .1098 \\
\hline Posterior, d-5 scan & 89.38 & 3.536 & .2979 & .1179 & .2012 & .0824 & -.1122 & -.4999 & - \\
\hline Dorsal, d-1 scan & 87.31 & 3.280 & .3257 & 1.3626 & .1112 & - & -.1667 & -.7409 & .2106 \\
\hline Dorsal, d-5 scan & 88.21 & 3.607 & .3138 & 1.7322 & .1285 & - & -.0648 & -.6808 & .1624 \\
\hline Blade, d-1 scan & 88.32 & 5.661 & .3058 & -1.277 & .0249 & .0430 & -.1581 & -.5576 & .3198 \\
\hline Blade, d-5 scan & 92.22 & 5.484 & .2426 & .7315 & .0324 & - & -.0845 & -.3685 & .1972 \\
\hline \multicolumn{10}{|l|}{ Percentage of lean } \\
\hline Posterior, d-1 scan & 76.39 & 5.750 & 2.016 & 48.049 & 1.2989 & .3662 & -1.1987 & -4.3966 & -2.4755 \\
\hline Posterior, d-5 scan & 75.29 & 5.012 & 2.062 & 47.449 & 1.3219 & .4809 & -.7112 & -3.7087 & -2.8412 \\
\hline Dorsal, d-1 scan & 69.88 & 3.004 & 2.255 & 55.780 & .7889 & - & -1.0977 & -4.8939 & -1.7345 \\
\hline Dorsal, d-5 scan & 72.33 & 3.131 & 2.162 & 58.057 & .9030 & - & -.4757 & -4.3887 & -2.0980 \\
\hline Blade, d-1 scan & 71.91 & 5.777 & 2.199 & 37.026 & .1810 & .3461 & -1.1314 & -4.1066 & -1.0257 \\
\hline Blade, d-5 scan & 81.58 & 6.721 & 1.774 & 48.200 & .2264 & .1921 & -.7101 & -2.5512 & -1.9354 \\
\hline
\end{tabular}

aThe weight loss between time of $d-5$ scanning and time of dissection.

${ }^{\mathrm{b}} \mathrm{CD}=$ coefficient of determination.

${ }^{{ }^{C} \mathrm{Cp}}=$ Mallows' Cp statistic for model selection.

$\mathrm{d}_{\mathrm{RSD}}=$ residual standard deviation (kilograms), percentage on bottom half. 
and 6). Using fat-free lean as the end point for predicting weight of lean did not increase the $C D$, and in most cases, the $C D$ were slightly reduced.

In summary, it seems that although the BLD orientation yielded the best $\mathrm{CD}$ and lowest RSD, the advantages over the DOR and POS orientations are minimal. Adjusting the lean end point for any dehydration may be a useful step when predicting lean content. Calculating a fat-free lean end point does not improve the CD or decrease the RSD for lean weight; it is beneficial when predicting lean percentage.

\section{Implications}

Orientation is not a major factor when scanning the rib cut as long as it is consistent for each scan. The calculated lean end point used as the dependent variable can become an important factor, especially if major dehydration has occurred or there is significant cutting losses. Calculation of fat-free lean seems to be more accurate when percentage lean is being predicted.

\section{Literature Cited}

AOAC. 1990. Official Methods of Analysis (15th Ed.). Association of Official Analytical Chemists, Washington, DC.
Fiorotto, M. L., W. L. Cochran, R. C. Funk, H.-P. Sheng, and W. J. Klish. 1987. Total body electrical conductivity measurements: Effects of body composition and geometry. Am. J. Physiol. 252: R794.

Forrest, J. C., C. H. Kuei, M. W. Orcutt, A. P. Schinckel, J. R. Stouffer, and M. D. Judge. 1989. A review of potential new methods of on-line pork carcass evaluation. J. Anim. Sci. 67: 2164.

Gwartney, B. L., C. R. Calkins, R. J. Rasby, and J. C. Forrest. 1992. Predicting lean content of beef cuts using electromagnetic scanning. J. Anim. Sci. 70(Suppl. 1):56 (Abstr.).

Hankins, I. G., and P. E. Howe. 1946. Estimation of the composition of beef carcasses and cuts. Tech. Bull. 926. Washington, DC.

Khaled, M. A., M. J. McCutcheon, J. Canlas, and C. E. Butterworth. 1985. Effects of body geometry on TOBEC measurement. In: Proc. 4th South. Biomed. Conf. p 171. Plenum, New York.

Klish, W. J., G. B. Forbes, A. Gordon, and W. J. Cochran. 1984. New method for estimation of lean body mass in infants (EMME instrument): Validation in nonhuman models. J. Pediatr. Gastroenterol. Nutr. 3:199.

Lin, R. S., J. C. Forrest, M. D. Judge, and R. P. Lemenager. 1992. Application of electromagnetic scanning for lean prediction in beef primal cuts. J. Anim. Sci. 70(Suppl. 1):220 (Abstr.).

Mallows, C. L. 1973. Some comments on Cp. Technometries 15:661.

Pethig, R. 1979. Dielectric and Electronic Properties of Biological Materials. p 225. Wiley, New York.

SAS. 1990. SAS User's Guide: Statistics (Version 6.06 Ed.). SAS Inst. Inc., Cary, NC.

USDA. 1988. Institutional Meat Purchase Specifications. USDA, Washington, DC. 